\title{
Chronology of the Translated Orations
}

I present here an overview of the dates I have adopted for the translated orations. Arguments may be found in the Introduction.

$\begin{array}{ll}\text { early } 340 \text { S } & \text { Oration } 24 \\ \text { no later than early } 350 \text { ? } & \text { Oration } 30 \text { (but see below) } \\ \text { fall } 355 & \text { Oration 20 } \\ 355-56 ? & \text { Oration 21 } \\ \text { late } 350 \text { s? } & \text { Oration } 26 \\ \text { ca. } 360 & \text { Oration 23 } \\ \text { ca. } 360 & \text { Oration 29 } \\ 360 ? & \text { Oration } 33 \\ \text { early } 380 \text { os? } & \text { Oration } 30 \text { (but see above) } \\ 383-384 & \text { Oration } 17 \\ 383-385 & \text { Oration } 31 \\ \text { ca. } 385 & \text { Oration } 34 \\ \text { Undatable } & \text { Oration 22 } \\ \text { Undatable } & \text { Oration 25 } \\ \text { Undatable } & \text { Oration 27 } \\ \text { Undatable } & \text { Oration } 28 \\ \text { Undatable } & \text { Oration } 32\end{array}$


